ИЗВЕСТИЯ АКАДЕМИИ НАУК ЭСТОНСКОИ ССР. ТОМ 30 Химия. 1981, № 3

\title{
ХАРАКТЕРИСТИКА СОСТАВА СЛАНЦЕВОЙ СМОЛЫ КАМЕРНЫХ ПЕЧЕЙ
}

Смола, получаемая в результате разложения эстонского горючего сланца кукерсита в камерных печах при высокой температуре $850{ }^{\circ} \mathrm{C}$ (деструкция с целью производства газа), исследована сравнительно мало. Известно несколько работ по изучению влияния технологического режима камерных печей на качество смол, а также по химическому групповому составу легко-средних фракций $\left(200-350^{\circ}\right)$ [']. Имеются данные о количественном содержании некоторых индивидуальных компонентов [ $\left.{ }^{2}\right]$.

Целью исследования было выяснить разницу в составе высокотемпературной и низкотемпературной (смола полукоксования) смол и на основе полученных результатов сделать выводы о реакциях, протекающих при высокой температуре, и о ее влиянии на состав смолы. Объектом исследования служила смола промышленных камерных печей, полученная из ПО «Сланцехим» им. В. И. Ленина в г. Кохтла-Ярве.

В табл. 1 представлены сравнительные данные смолы полукоксования, полученной в лабораторной алюминиевой реторте. В камерных печах основное количество первичной смолы превращается в газ, поэтому выход смолы на кероген в 5 раз меньше, чем выход смолы полукоксования. Анализ проводился по общей схеме, примененной уже ранее при исследовании состава продуктов термической деструкции топлив и битумоидов [ $\left.{ }^{3}\right]$. Кислые соединения отделяли от смолы щелочью. Для разделения смолы на группы применялась препаративная тонкослойная хроматография (ТCX), а индивидуальный состав групп определяли газохроматографически. Для препаративной ТСX использовались пластинки $(24 \times 24$ см) с незакрепленным слоем адсорбента $(2$ мм). Для идентификации и разделения полос соединений пластинки просматривались с помощью дневного и ультрафиолетового света при 365 нм. Суммарную нейтральную смолу разделяли на группы на сили-

Таблица 1

Характеристика смол камерных печей и полукоксования

\begin{tabular}{c|c|c}
\hline Показатели & $\begin{array}{c}\text { Камерные } \\
\text { печи }\end{array}$ & $\begin{array}{c}\text { Полукок- } \\
\text { сование }\end{array}$ \\
\hline
\end{tabular}

Выход смолы на кероген, \%

Показатель преломления, $n_{D}^{02}$

Плотность, $\mathrm{Q}_{4}^{20}$

Групповой состав, вес. $\%$ :

парафины

олефины

алкилбензолы

конденсированные ароматические углеводороды

нейтральные кислородные соединения

фенолы
13,1

1,599

1,037

4,1

4,3

13,4

28,6

33,6

16,0
65,2

1,530

0,955

8,1

6,8

6,0

19,8

32,8

26,5 
кагеле $L(40-100$ мкм), в качестве элюента использовали $н$-гексан. Содержание парафинов, олефинов и фенолов в смоле камерных печей меньше, а ароматических соединений (низкокипящих алкилбензолов и полициклических ароматических углеводородов) - значительно больше, чем в смоле полукоксования. Такая закономерность не была неожиданной, так как в камерных печах сланец подвергается действию высокой температуры и при этом происходит крекинг первичных продуктов разложения.

Индивидуальный состав выделенных групп исследовали на «Хром$41 »$ с пламенно-ионизационным детектором в условиях программирования температуры. Общую характеристику предварительно получили на параллельных насадочных колонках, а для более детальной идентификации применяли капиллярные. Газом-носителем служил гелий (скорость 2 мл/мин), деление газового потока на входе в колонку $1: 500$. Качественная расшифровка хроматограмм осуществлялась добавкой к исследуемой смеси индивидуальных соединений, а также по индексам удерживания, приведенным в литературе [4-6]. Как показывает рис. 1, главными компонентами парафино-олефиновой фракции смолы камерных печей являются $H$-парафины и соответствующие 1-олефины. Максимальное число атомов углерода в цепи - 26. До $\mathrm{C}_{17} \mathrm{\kappa oн-}$ центрация основных компонентов существенно не отличается. Начиная с $\mathrm{C}_{17}$, содержание н-углеводородов резко падает и с дальнейшим ростом углеродной цепи равномерно уменьшается. Содержание н-парафинов с нечетным числом атомов углерода во фракции больше, а среди олефинов концентрация соединений с четным числом атомов угле-

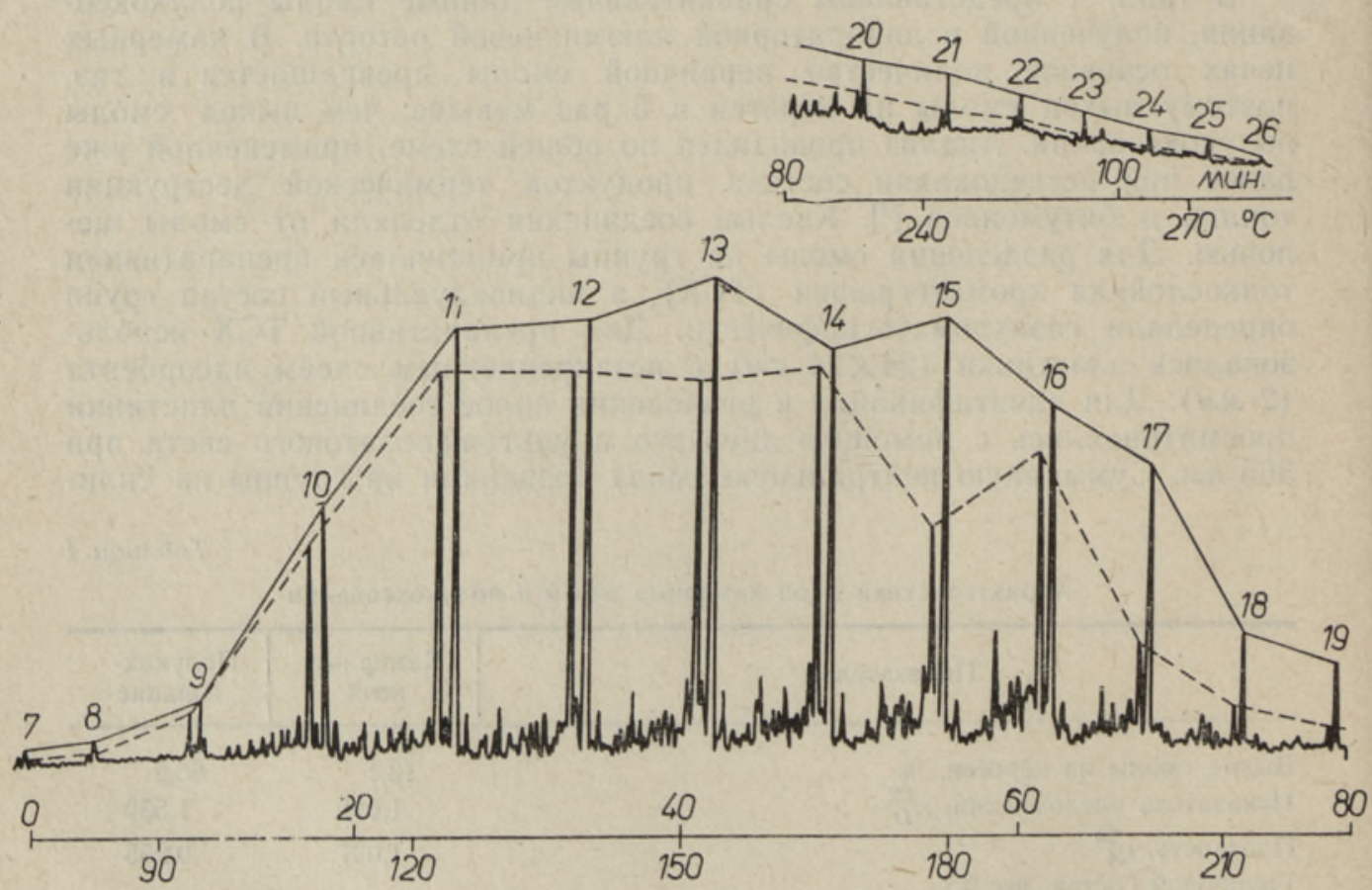

Рис. 1. Хроматограмма выделенной в тонком слое парафино-олефиновой фракцин смолы. Длина колонки 50 м; внутренний диаметр 0,25 мм; скорость подъема температуры 2 град/мин; неподвижная фаза - OV-101. Цифры на хроматопрамме обозначают число атомов углерода в молекуле $\boldsymbol{H}$-алкенов и $H$-1-олефинов. Пнки олефинов соединены штриховой линией, пики парафннов - сплошной. 
Состав ароматических углеводородов $\mathrm{C}_{8}$

\begin{tabular}{|c|c|c|c|}
\hline Название соединения & $\begin{array}{c}\text { Газбензин } \\
\text { камерной } \\
\text { печи }\end{array}$ & $\begin{array}{c}\text { Смола полу- } \\
\text { коксования } \\
\text { сланца }\end{array}$ & $\begin{array}{l}\text { Каменно- } \\
\text { угольная } \\
\text { смола [10] }\end{array}$ \\
\hline $\begin{array}{l}\text { Этилбензол } \\
n \text {-Ксилол } \\
\text { м-Конлол } \\
o-\text { Ксилол }\end{array}$ & $\begin{array}{l}29,4 \\
18,1 \\
27,6 \\
24,9\end{array}$ & $\begin{array}{l}35,3 \\
37,3 \\
27,4\end{array}$ & $\begin{array}{r}2,7 \\
4,0 \\
86,0 \\
7,3\end{array}$ \\
\hline
\end{tabular}

рода $\left(\mathrm{C}_{14}\right.$ и $\left.\mathrm{C}_{16}\right)$ выше. Те же общие закономерности наблюдаются и при исследовании смолы полукоксования [ [7]. Из вышеизложенного следует, что состав фракций алифатических углеводородов смолы камерных печей и смолы, полученной при низкой температуре, сходен. То, что содержание олефинов в интервале $\mathrm{C}_{7}-\mathrm{C}_{19}$ несколько меньше их содержания в интервале $\mathrm{C}_{10}-\mathrm{C}_{12}$, объясняется крекингом длинных цепей. Так как всетаки в обеих смолах относительные содержания индивидуальных $\mu$-парафинов и соответствующих 1-олефинов почти одинаковы, то можно сделать вывод, что эти соединения имеют одинаковую стабильность как при низкой, так и при повышенной температуре. Преобладание среди изомеров-олефинов 1-олефинов указывает на то, что при высокой температуре не происходит изомеризации двойной связи. Содержание олефинов, имеющих двойную связь в середине цепи, даже меньше, чем в смоле полукоксования. Возможно, что соединения, имеющие двойную связь в среднем положении, при повышенной температуре менее стабильны и расщепляются; кроме того, в камерных печах разлагается также первичная тяжелая смола, содержащая много длинных $н$-алкильных цепей $\left.{ }^{8}\right]$. Из них образуется дополнительное количество 1-олефинов, что повышает их концентрацию. Последнее предположение более правдоподобно.

Установлено, что длинные алкильные цепи отщепляются не полностью, в смоле присутствует небольшое количество алкилбензолов, содержащих в боковых н-алкильных цепях 10-17 атомов углерода. Анализ на капиллярной колонке показал, что эти соединения представлены четырьмя гомологическими рядами. Для более подробной характеристики низкокипящих алкилбензолов провели анализ газбензина камерной печи, в составе которого было $(\%): 76,0$ бензола,

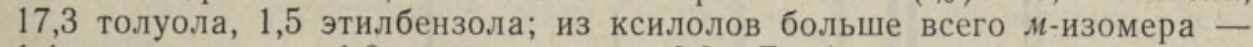
1,4, o-ксилола - $1,3, n$-ксилола - 0,9. Газбензин также содержит $H$-пропилбензол - 0,3, изо-пропилбензол - $0,1, n$ - и $м$-метил-этилбензолы - 0,9 и $о$-метил-этилбензол - 0,3\%. В табл. 2 приведены относительные содержания моноциклических ароматических углеводородов $\mathrm{C}_{8}$ в газбензине камерных печей, в продуктах низкотемпературного термолиза кукерсита и в каменноугольной смоле.

В смоле камерных печей по сравнению со смолой полукоксования содержание этилбензола меньше, что указывает на влияние термического разложения. Содержание 0 -ксилола также меньше, а $\boldsymbol{M}$-ксилола больше. В продуктах полукоксования малопревращенных топлив сапропелитового типа главный изомер о-ксилол [ $\left.{ }^{9}\right]$, предполагается также, что в исходном керогене у циклических структур боковые цепи находятся преимущественно в ортоположениях. Данные о составе ксилолов камерных печей показывают, что при высокой температуре про- 

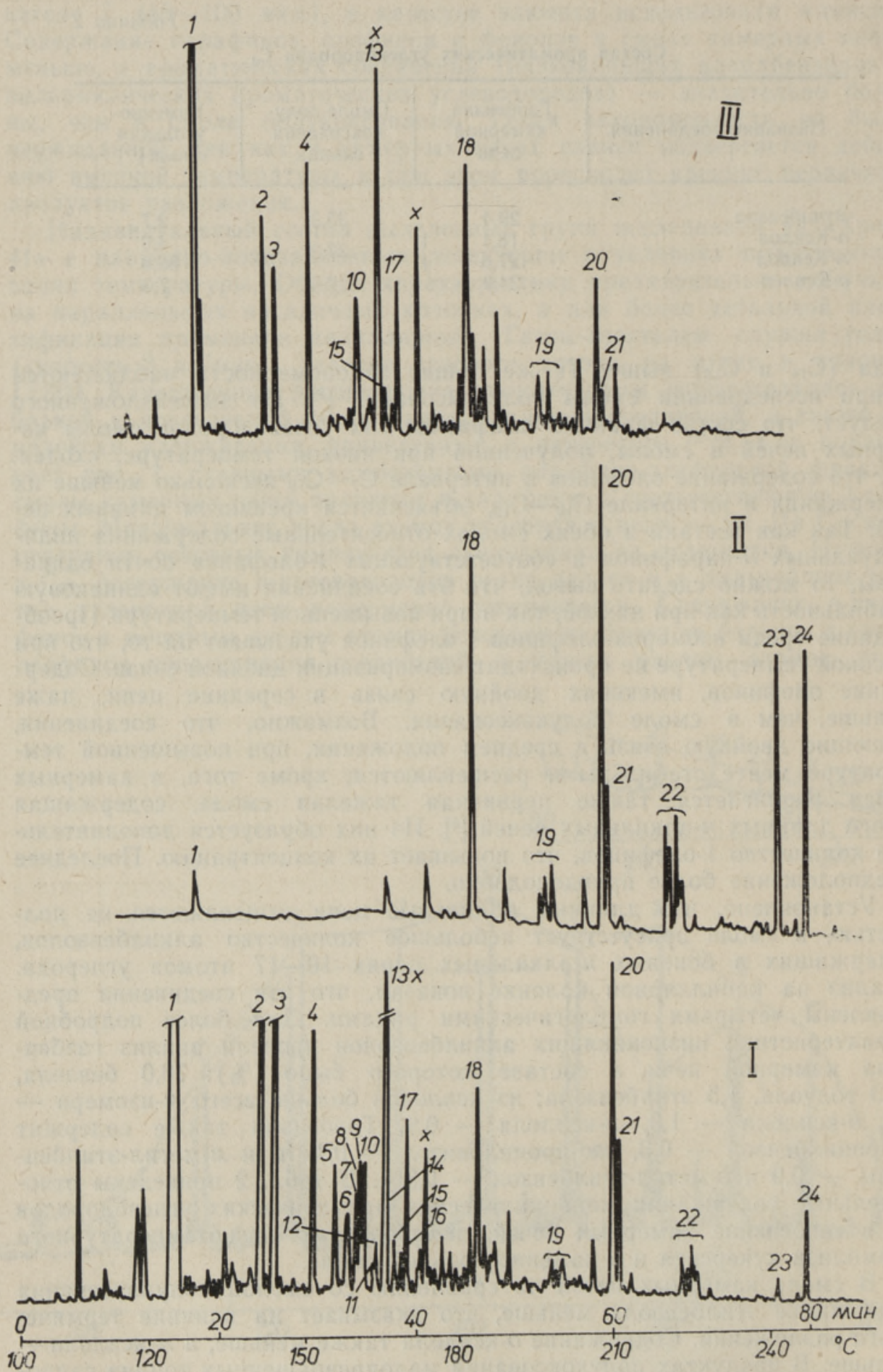

Рнс. 2. Хроматопраммы полициклических ароматических углеводородов, разделенных TCX на окиси алюминия. I - исходная группа, выделенная из смолы. Фракции, выделенные на окиси алюминия; II - антрацен-фенантреновая; III - флуоренаценафтеновая. Длина колонки 50 м; внутренний диаметр 0,25 мм; скорость подъема 
исходит в некоторой мере и изомеризация в метаположение - термодинамически самое стабильное.

Полицикличсские ароматические углеводороды составляют самую большую и характерную группу смолы. Эта группа подвергалась дополнительному разделению для более точного анализа. По литературным данным, в качестве адсорбентов для ТCX полициклических ароматических соединений применяются главным образом силикагель и окись алюми:лия $\left[{ }^{11,12}\right]$. Для модификации адсорбента применяются различные вещества, например, пикриновая кислота $\left[{ }^{13,14}\right]$. В настоящей работе изучасмую группу разделяли вторично как на силикагеле, так и на окиси алюминия. Элюирование проводили смесью $H$-гексана и хлороформа (в соотношении $85: 15)$. Эталонными веществами служили антрацен, хризен, 3,4-бензпирен и коронен. При вторичном разделении из группы полициклических ароматических углеводородов выделили фракции соединений, которые разделяются в зависимости от количества и характера циклов. Распределение структур исходной группы в порядке увеличения их адсорбируемости следующее $(\%)$ : алкилбензолы - 3 , бициклическая ароматика типа индена и тетралина - 6 , нафталин, метил- и диметилнафталины - 46, трициклическая - типа флуорена и аценафтена - 15, антрацен-фенантреновая - 15. Фракции, адсорбируемые в большей степени, содержали лишь небольшое количество летучих соединений (флуорантен, пирен). Представленные ниже хроматограммы показывают, что фракции, содержащие различные структуры, селективно разделены. Таким образом, находмт подтверждение общепринятый принцип, что двукратное разделение более эффективно, если при вторичном разделении применять другой адсорбент. На рис. 2 отмечены основные индивидуальные компоненты и расположение соответствующих алкилизомеров главных структур. Хроматограммы показывают, что в смоле камерной печи содержится много нафталина, метил- и диметилнафталинов. Число индивидуальных компонентов меньше, чем в низкотемпературной смоле. Приведенные выше данные говорят о влиянии процессов деалкилирования на состав высокотемпературной смолы.

Некоторые основные компоненты флуореновой фракции (пики, обозначенные на рис. $2,{ }^{x}$ ) остались неидентифицированными. Так как пики отсутствуют на хроматограммах гидрированных проб, можно предположить, что данные компоненты - серусодержащие соединения. По литературным данным, в смоле камерной печи содержится $0,17 \%$ 3,4-бензпирена : $\left.{ }^{2}\right]$. По нашим данным, содержание 3,4-бензпирена в смоле относительно мало, примерно, в 5 раз меньше, чем дифенила.

Нейтральные кислородные соединения смолы камерной печи содержат в основном высококипящие соединения, так как первый значительный пик появляется на их хроматограмме при температуре колонки $250^{\circ}$. Часть пиков образует ряд. Так как пики эталонных кетонов с прямой цепью и пики компонентов исследуемой группы на хромато-

температуры 2 град/мин; неподвижная фаза - дексил 300.1 - нафталин; 2 2-метилнафталин; 3 - 1-метилнафталин; 4 - дифенил; 5 - 2-этилнафталин; $6-2,6-, 2,7$-диметилнафталин; $7-1,7$-диметилнафталин; 8 - 1,3-диметилнафталин; $9-1,6$-диметилнафталин; $10-2$-метилдифенил; $11-2,3$-диметилнафталин; 12 - 1,4-, 1,5-диметилнафталин; 13 - 4-метилдифенил; $14-1,2$-диметилнафталин; $15-3$-метилдифенил; 16 - 1,8-диметилнафталин; 17 - аценафтен; $18-$ флуорен; 19 - метилфлуорены; 20 - фенантрен; 21 - антрацен; 22 - метилфенантрены и метил-антращены; 23 - флуорантен; 24 - пирен; х - нендентифицированные сернистые соединения. 
грамме не совпадают, можно предположить, что кислородные соединения содержат кетоны с ароматическими структурами. Данные настоящей работы о составе фенолов совпадают с полученными ранее [15]. Фенолов в смоле мало (в смоле полукоксования - до 25\%). Они представлены в основном низкокипящими одноатомными фенолами (фенол, крезолы и ксиленолы), состав которых не отличается от состава фенолов каменноугольной смолы и смолы полукоксования большинства топлив сапропелитового типа. Полностью отсутствуют двухатомные фенолы типа 5-алкилрезорцинов - самые характерные компоненты смолы полукоксования кукерсита. Термическая нестабильность указанных структур общеизвестна. С другой стороны, количество низкокипящих одноатомных фенолов в пересчете на исходный сланец такое же, как и в смоле полукоксования.

\section{Выводы}

В ходе настоящей работы выяснились некоторые особенности камерной смолы. Выходы смолы в камерных печах и в установках полукоксования - соответственно 15 и $65 \%$ органического вещества. Нас интересовало, какие характеристики низкотемпературной смолы сохраняются при действии высокой температуры. Выяснилось, что состав длинноцепочечных парафинов и олефинов $\mathrm{C}_{11}-\mathrm{C}_{17}$ не меняется. Не происходит и изомеризации двойной связи. В смоле и газбензине камерной смолы отсутствуют н-углеводороды ниже $\mathrm{C}_{11}$, в то время как они составляют основную долю алифатических углеводородов низкотемпературной смолы. Отметим также, что и в смоле генераторов полукоксования отсутствуют $\boldsymbol{\mu}$-углеводороды, кипящие при температуре ниже $200^{\circ}$; при пиролизе тяжелой смолы они образуются в небольших количествах [8]. Это явление трудно объяснить - ведь короткоцепочечные углеводороды обычно более стабильны, чем длинноцепочечные. Содержание алкилбензолов с длинными боковыми цепями значительно меньше, а ксилолов - значительно больше, чем в низкотемпературной смоле. Отмечается некоторая изомеризация метилыных групп ксилолов, так как увеличивается содержание м-ксилола. Концентрация этилбензола неожиданно высокая.

Индивидуальный состав полициклических ароматических углеводородов такой же, как в низкотемпературной смоле, но доля алкилпроизводных меньше. В сумме с фенантреном антрацен составляет 19, а при полукоксовании - 30\%. Это понятно, так как антрацен легко подвергается реакциям конденсации (коксованию). Полное отсутствие в высокотемпературной смоле $н$-алкилкетонов, содержащихся в значительном количестве в смоле полукоксования, указывает на то, что алифатические карбонильные структуры при высокой температуре, очевидно, неустойчивы. Нейтральных кислородсодержащих соединений в высокотемпературной смоле весьма много, но они высококипящие, и ни одно соединение идентифицировать не удалось.

Авторы выражают благодарность С. Кивиряхк за проведение тонкослойного разделения.

\section{ЛИТЕ РА Т У Р А}

1. Е фи мов В. М., Пийк Э. Э., Соо М. О., В ахер Д. Х. О химическом групповом составе смол камерных печей. - В кн.: Химия и технология горючнх сланцев. Таллин, 1973, вып. 19, с. 73-77. 
2. Арро И. Х. О химическом составе ароматических углеводородов сланцевой смолы камерных печей. - Автореф. канд. дис., Таллин, 1964.

3. Klesment, I. Application of chromatographic methods in biogeochemical investigations. - J. Chromatogr., 1974, v. 91, N 2, p. 705-713.

4. Mostecký, J. P op l, M., K ŕ ižz, J. Determination of $\mathrm{C}_{12}$ alkylnaphtalenes and methylbiphenyls in aromatic fractions by capillary gas chromatography. - Anal. Chem., 1970, v. 42 , N 11, p. $1132-1135$.

5. Severson, R. F., Snook, M. E., Arrendale, R. F., Chortyk, O. T. Gas chromatographic quantitation of polynuclear aromatic hydrocarbons in tobacco smoke. - Anal. Chem., 1976, v. 48, N 13, p. 1866-1872.

6. L a o, R. C., Thom a s, R. S., O j a, H., D u b o is, L. Application of a gas chromatographic-mass spectrometer data processor combination to the analysis of the polycyclic aromatic hydrocarbon content of airborne pollutants. - Anal. Chem., 1973 , v. 45 , N 6, p. $908-915$.

7. Клесмент И., Риккен Ю., Эйз ен О. Состав тяжелой сланцевой смолы. Характеристика продуктов термолиза нейтральной части смолы. - Изв. АН ЭССР. Хим., Геол., 1976, т. 25, № 3, с. 186-192.

8. Клесмен т И. Состав алифатических структур тяжелой смолы полукоксования эстонского сланца-кукерсита. - Хим. тв. топл., 1975, № 4, с. 122-127.

9. Клесмент И., Риккен Ю., уров К. Характеристика оленского богхеда по данным термической деструкцин. - Хим. тв. топл., 1977, № 2, с. 126-132.

10. Pichler, H., Hennenberger, P., $\mathrm{S} \mathrm{chw}$ a $\mathrm{r} z, \mathrm{G}$. Untersuchung flüssiger und gasformiger Produkte der Steinkohlen-Schwelung. - Brennstoff-Chemie, 1968, Bd. 49 , N 6, S. $175-182$.

11. Kuch a r czyk, N., F ohl, J., V y mět a l, J. Dünnschichtchromatographie von aromatischen Kohlenwasserstoffen und einigen heterocyclischen Verbindungen. J. Chromatogr., 1963, v. 11, N 1, p. 55-61.

12. Pop l, M., Moste cký, J., D ol a n ský, V., Kuraš, M. Adsorption elution chromatography of alkylbenzenes on alumina. - Anal. Chem., 1971, v. 43, N 4, p. $518-521$.

13. Kessler, H., Müller, E. Dünnschichtchromatographische Trennung mehrkerniger Aromaten mit Pikrinsäure als Komplexbildner. - J. Chromatogr., 1966, v. 24, N 2, p. $469-472$.

14. Berg, A., L a m, J. Separation of polycyclic aromatic hydrocarbons by thin-layer chromatography on impregnated layers. - J. Chromatogr., 1963, v. 16, N 1, p. $157-166$.

15. Лилле Ю. Э. Исследования в области алкилрезорцинов. Автореф. докт. дис., Таллин, 1973.

\author{
Ннститут химии \\ Академии наук Эстонской ССР
}

Поступила в редакцию 10/IV 1980

\author{
Saima SALUSTE, I. KLESMENT
}

\title{
KAMBERAHJUDES TOODETUD POLEVKIVIOLLI ISELOOMUSTUS
}

On esitatud preparatiivse ōhukese kihi kromatograafia ja kapillaargaasikromatograafia teel saadud andmed kamberahjudes toodetud kukersiidiôli rühma- ja individuaalkoostise kohta ning iseloomustatud kamberahjudes kulgevaid sekundaarseid lagunemis- ja aromatiseerumisprotsesse. Oli ei sisalda $\mathrm{C}_{11}$-st madalamaid $n$-süsivesinikke ja $n$-alküülketoone, pikkade külgahelatega alküülbenseene on vähe. Polütsükliliste aromaatsete süsivesinike alküülisomeeride hulk on väiksem kui poolkoksistamisel toodetud ōlis, ksüloolide hulk aga suurem.

\section{Saima SALUSTE, I. KLESMENT}

\section{CHARACTERIZATION OF SHALE OIL FROM CHAMBER FURNACES}

Data are presented about the group and individual composition of shale oil produced in chamber furnaces by a high-temperature decomposition of kukersite. The investigations were performed with the use of chromatographic methods. A characterization of secondary decomposition and aromatization processes is given. 